\title{
EVALUASI ASPEK TRANSPORTASI TEMPAT PERISTIRAHATAN DI KM 97 TOL CIPULARANG
}

\author{
Ni Luh Putu Shinta Eka Setyarini ${ }^{1}$, M. I. Dewi Linggasari ${ }^{2}$, Hendra Susanto ${ }^{3}$ \\ ${ }^{1}$ Program Studi Sarjana Teknik Sipil, Fakultas Teknik, Universitas Tarumanagara \\ Email:niluhs@ft.untar.ac.id \\ ${ }^{2}$ Program Studi Sarjana Teknik Sipil, Fakultas Teknik, Universitas Tarumanagara \\ Email:dewil@ft.untar.ac.id \\ ${ }^{3}$ Program Studi Sarjana Teknik Sipil, Fakultas Teknik, Universitas Tarumanagara \\ Email:hen_susanto@yahoo.com
}

Masuk: 16-04-2019, revisi: 25-06-2019, diterima untuk diterbitkan: 12-09-2019

\begin{abstract}
ABSTRAK
Padatnya kendaraan dan lamanya perjalanan di ruas jalan Tol Cipularang (sekitar 57,5 km) dapat membuat pengemudi merasa jenuh dan menurunnya konsentrasi. Mengemudikan kendaraan dalam keadaan jenuh dapat membahayakan diri sendiri dan orang lain. Turunnya konsentrasi dapat menyebabkan pandangan yang kurang baik sehingga menimbulkan kecelakaan. Jadi istirahat merupakan salah satu kebutuhan yang sangat penting dalam berkendara. Sesuai PP No.15 tahun 2005, tentang persyaratan teknis pembangunan jalan tol, bahwa harus tersedia tempat istirahat dan pelayanan untuk kepentingan pengguna jalan tol paling sedikit 1 untuk setiap jarak $50 \mathrm{~km}$ setiap jurusan. Hadirnya tempat peristirahatan KM 97 di Tol Cipularang dapat membantu pengemudi dan penumpang untuk memenuhi segala kebutuhan pribadi. Permasalahannya adalah bagaimana pengelola dari tempat peristirahatan melayani pengunjung untuk memenuhi kebutuhan di tempat peristirahatan. Standar Pelayanan Minimal (SPM) adalah pedoman yang mengatur standar dari pelayanan tempat peristirahatan. Setiap tempat peristirahatan belum tentu memiliki fasilitas dan pelayanan yang sama. Oleh sebab itu perlu dilakukan evaluasi terhadap fasilitas dan pelayanan tempat peristirahatan KM 97 Tol Cipularang. Metode yang akan digunakan adalah pengukuran kualitas layanan dengan metode importance performance analysis (IPA). Kebutuhan parkir pada hari Minggu $=375$ kendaraan $>$ daripada kapasitas parkir $=321$ kendaraan yang tersedia . Tingkat kepuasan responden terhadap seluruh poin mengenai keandalan dari infrastruktur tempat peristirahatan baik dari segi aspek transportasi maupun fasilitas pelayanan mendapatkan nilai sebesar 80,32\% yang berarti sangat baik.
\end{abstract}

Kata kunci: Tempat Peristirahatan; fasilitas; memenuhi kebutuhan

\begin{abstract}
The density of the vehicle and the length of trip on the Cipularang Toll Road (around $57.5 \mathrm{~km}$ ) can make the driver feel bored and decrease concentration. Driving a vehicle in a saturated state can endanger yourself and others. The decrease in concentration can cause unfavorable views, causing accidents. So resting is one of the most important needs in driving. In accordance with Government Regulation No.15 of 2005, regarding the technical requirements of toll road construction, that there must be a place of rest and services for the benefit of toll road users at least 1 for every $50 \mathrm{~km}$ distance in each direction. The presence of the KM 97 resting place in Cipularang Toll Road can help drivers and passengers to meet all their personal needs. The problem is how the manager of the resort serves visitors to meet the needs of the resort. Minimum Service Standards (SPM) are guidelines that govern the standards of resort services. Each resort does not necessarily have the same facilities and services. Therefore it is necessary to evaluate the facilities and services of the Cipularang Toll KM 97 resting place. The method to be used is the measurement of service quality with the importance performance analysis (IPA) method. Parking needs on Sundays $=375$ vehicles $>$ rather than parking capacity $=321$ available vehicles. The level of satisfaction of respondents to all points regarding the reliability of the infrastructure of the resort both in terms of aspects of transportation and service facilities get a value of $80.32 \%$ which means very good.
\end{abstract}

Keywords: Resting Place; amenities; make ends meet 


\section{PENDAHULUAN}

Kehadiran jalan tol Cipularang merupakan langkah untuk mempersingkat waktu tempuh dari Jakarta ke Bandung. Jalan tol ini mulai operasional pada akhir April 2005. Tol ini berlokasi di daerah dataran tinggi sehingga geometrik jalannya menjadi naik-turun dan juga memerlukan banyak jembatan yang panjang dan tinggi sebagai penghubung. Pembangunan jalan tol CIPULARANG dibagi menjadi 2 tahap. Tahap I adalah ruas jalan Tol Cikampek-Sadang yang operasional 1 Agustus 2003 dan Padalarang-Cikamuning pada 21 September 2003 dengan panjang 17,5 km serta kedua ruas Tol Sadang-Cikamuning tahap II yang operasional 26 April 2005 dengan panjang $41 \mathrm{~km}$. Dalam kondisi normal dengan kecepatan rata-rata $80 \mathrm{~km} / \mathrm{jam}$ melalui tol CIPULARANG, jarak Jakarta-Bandung hanya membutuhkan waktu tempuh sekitar 2 jam dengan Cawang sebagai titik awal.

Menurut PP No.15, 2005 tentang Minimum Pelayanan Jalan Tol maka ruas jalan tol Cipularang dengan panjang $57,5 \mathrm{~km}$ diharuskan adanya tempat peristirahatan untuk beristirahat sementara bagi pengemudi dan penumpang. Bahwa pada jalan tol harus tersedia tempat istirahat dan pelayanan untuk kepentingan pengguna jalan tol paling sedikit 1 untuk setiap jarak 50 kilometer untuk setiap ruas dan jurusan. Dengan beristirahat maka dapat mengurangi juga resiko kecelakaan yang diakibatkan oleh menurunnya konsentrasi pengemudi. Maka dari itu adanya suatu tempat peristirahatan di jalan tol sangatlah penting bagi kelancaran arus lalu lintas dan mencegah kecelakaan.

Tempat peristirahatan sudah pasti harus memiliki fasilitas yang lengkap dan nyaman agar dapat memenuhi kebutuhan pengguna jalan tol. Rasa aman dan nyaman dapat dirasakan apabila fasilitas di rest area sudah memenuhi kebutuhan pengguna jalan tol. Perlu dilakukan studi agar dapat mengetahui kualitas dari rest area dan tingkat kepuasan dari para pengguna jalan tol. Evaluasi dapat dilakukan setelah mengetahui kelengkapan fasilitas dan kondisi dari rest area sehingga diharapkan keperluan pengguna jalan tol dapat terpenuhi dari jumlah dan kualitas.

\section{Batasan Penelitian}

Penelitian ini dibatasi pada pengaruh kesiapan integrasi suatu fasilitas tempat peristirahatan dari aspek transportasi dengan kepuasan pengguna jalan tol CIPULARANG, dengan lokasi penelitian di KM 97. Pengumpulan data dilaksanakan dengan metode observasi dan kuesioner langsung serta on line dengan jumlah responden 100 orang.

\section{Rumusan Masalah}

Permasalahan dalam penelitian adalah adanya kesenjangan antara kenyataan dengan indikator kelayakan yang disyaratkan oleh standar fasilitas tempat peristirahatan. Sehingga permasalahan yang diangkat dalam penelitian ini adalah:

1. Bagaimanakah standar fasilitas tempat peristirahatan terhadap SPM (Standar Pelayanan Minimal)?

2. Bagaimanakah sirkulasi di lokasi dan lingkungan tempat peristirahatan terhadap integrasi pada sistem transportasi?

3. Apakah kapasitas parkir dapat menampung jumlah pengunjung?

\section{Tujuan Penelitian}

Penelitian ini bertujuan untuk menganalisis:

1. Kapasitas parkir, jam puncak, dan jumlah pengguna kendaraan dari aspek transportasi

2. Evaluasi pelayanan fasilitas di tempat istirahat berdasarkan SPM

3. Hubungan pelayanan fasilitas dengan kepuasan pengguna jalan tol

4. Hubungan kepuasan pengguna jalan tol dengan SPM 


\section{METODE PENELITIAN \\ Metode Pengumpulan Data}

Tempat istirahat yang menjadi lokasi dari penelitian adalah KM 97 Tol CIPULARANG yang menjadi tujuan pengemudi apabila menempuh perjalanan dari arah Bandung menuju Jakarta. Pengumpulan data berupa data primer akan dilaksanakan dengan cara pengamatan langsung seperti: kapasias parkir, durasi parkir, indeks parkir,jam puncak dan sirkulasi parkir. Selain pengamatan langsung data juga diperoleh dari kuesioner yang disebarkan secara langsung di lokasi dan melalui on line. Data sekunder diperoleh dari pengelola tempat peristirahatan KM 97, berupa data petak parkir, sirkulasi lalulintas, site layout.

\section{Durasi Parkir}

Untuk mengetahui rata-rata lamanya parkir dari seluruh kendaraan selama waktu survei dapat digunakan rumus berikut:

$\mathrm{DP}=\mathrm{Ex}-\mathrm{En}$

dengan DP = Durasi parkir (menit), Ex = Waktu saat kendaraan keluar dari ruang parkir (menit), En = Waktu saat kendaraan masuk ke ruang parkir (menit).

\section{Indeks Parkir}

Indeks parkir dirumuskan sebagai berikut:

Ip $=\frac{\text { Akumulasi Parkir }}{\text { Ruang Parkir Tersedia }}$

Dimana akumulasi parkir didapat dari:

Akumulasi $=$ Kendaraan di Lokasi + Kendaraan Masuk - Kendaraan Keluar

- IP $<1$ artinya bahwa fasilitas parkir tidak bermasalah, dimana kebutuhan parkir tidak melebihi daya tampung/kapasitas normal.

- IP = 1 artinya bahwa kebutuhan parkir seimbang dengan daya tampung/kapasitas normal.

- IP > 1 artinya bahwa fasilitas parkir bermasalah, dimana kebutuhan parkir melebihi daya tampung/kapasitas normal.

\section{Jam Puncak}

Jam puncak adalah jam terpadat akan volume kendaraan yang datang ke rest area. Untuk mendapatkan jam puncak, diperlukan survei lapangan dengan menghitung waktu kendaraan masuk dan jumlah kendaraan yang keluar masuk. Jam puncak akan ditentukan berdasarkan volume kendaraan terbanyak di waktu tertentu pada saat survei. Di tempat peristirahatan Cipularang KM 97 dari arah Bandung menuju Jakarta, jam puncaknya ialah hari minggu jam 13.00-17.00.

\section{Site Layout}

Site Layout adalah denah dari tempat peristirahatan yang menggambarkan tata letak tempat yang terdiri dari fasilitas-fasilitas yang tersedia di dalamnya. Fasilitas tersebut berupa rumah makan, tempat parkir, SPBU, toilet, taman bermain, tempat ibadah, tempat wisata, kios dll.

Dengan adanya denah gambar maka penelitian di lapangan akan menjadi lebih mudah. Dari denah dapat diketahui tata letak fasilitas-fasilitas tertentu, tempat parkir dan jalan akses di dalam rest area. Denah dapat mempermudah penelitian sirkulasi/arus jalan di dalam tempat peristirahatan. 
Selain aspek transportasi dengan pengamatan langsung, juga dilaksanakan mewawancara para pengunjung dengan kuestioner untuk mendapatkan nilai tingkat kepuasan responden terhadap fasilitas pelayanan dimana indikator pertanyaan berdasarkan standar pelayanan minimal (SPM). SPM untuk tempat peristirahatan katagori A dapat dilihat pada tabel 1.

Tabel 1. Stanndar Pelayanan Minimal (SPM) Kategori A

\begin{tabular}{|c|c|c|c|c|}
\hline \multirow{8}{*}{$\begin{array}{l}\text { Tempat Istirahat (TI), } \\
\text { dan Tempat Istirahat dan } \\
\text { Pelayanan (TIP) }\end{array}$} & Kondisi Jalan & $\begin{array}{l}\text { Seluruh Permukaan } \\
\text { Jalan di Tempat Istirahat }\end{array}$ & $\begin{array}{l}\text { Tidak Ada } \\
\text { Lubang,Retak dan Pecah }\end{array}$ & $\begin{array}{l}\text { Waktu toleransi } \\
\text { pemenuhan } 2 \times 24 \text { jam }\end{array}$ \\
\hline & On/Off Ramp & $\begin{array}{l}\text { Permukaan Jalan di } \\
\text { Jalur Masuk dan Keluar } \\
\text { Tempat Istirahat }\end{array}$ & $\begin{array}{l}\text { Tidak Ada } \\
\text { Lubang,Retak dan Pecah }\end{array}$ & $\begin{array}{l}\text { Waktu toleransi } \\
\text { pemenuhan } 2 \times 24 \text { jam }\end{array}$ \\
\hline & Toilet & Fungsi dan Manfaat & Berfungsi $100 \%$ & $\begin{array}{l}\text { Waktu toleransi } \\
\text { pemenuhan } 2 \times 24 \text { jam }\end{array}$ \\
\hline & Parkir Kendaraan & Fungsi dan Manfaat & Berfungsi $100 \%$ & $\begin{array}{l}\text { Jalan dan perparkiran } \\
\text { hanya diperuntukkan } \\
\text { bagi pengguna jalan tol }\end{array}$ \\
\hline & Penerangan & Fungsi dan Manfaat & Berfungsi $100 \%$ & $\begin{array}{l}\text { Mengacu pada standar } \\
\text { PJU }\end{array}$ \\
\hline & $\begin{array}{l}\text { Stasiun Pengisian } \\
\text { Bahan Bakar }\end{array}$ & Fungsi dan Manfaat & Berfungsi $100 \%$ & $\begin{array}{l}\text { Mengacu kepada } \\
\text { ketetapan ESDM }\end{array}$ \\
\hline & Bengkel Umum & Fungsi dan Manfaat & Berfungsi $100 \%$ & $\begin{array}{l}\text { Bengkel harus memiliki } \\
\text { ijin usaha }\end{array}$ \\
\hline & $\begin{array}{l}\text { Tempat Makan dan } \\
\text { Minum }\end{array}$ & Fungsi dan Manfaat & Berfungsi $100 \%$ & $\begin{array}{l}\text { Wajib memberikan } \\
\text { informasi harga } \\
\text { makanan dan minuman } \\
\text { yang dijual }\end{array}$ \\
\hline
\end{tabular}

\section{Metode Analisis Data}

Untuk menjawab masalah mengenai sampai sejauh mana keandalan infrastruktur tempat peristirahatan, maka digunakan Importance Performance Analysis/Analisis Kuadran. Analisis tersebut adalah sebuah teknik analisis deskriptif yang diperkenalkan oleh John A. Martilla dan John C. James tahun 1977. Importance Performance Analysis adalah suatu teknik analisis yang digunakan untuk mengidentifikasi faktor-faktor kinerja penting apa saja yang harus ditujukan.

Metode yang digunakan untuk mengolah data persepsi dari pengunjung adalah dengan Importance Performance Analysis/Analisis Kuadran (IPA). Analisis tersebut adalah sebuah teknik analisis deskriptif yang diperkenalkan oleh John A. Martilla dan John C. James tahun 1977. Importance Performance Analisis adalah suatu teknik analisis yang digunakan untuk mengidentifikasi faktor-faktor kinerja penting apa saja yang harus ditujukan. Dibawah ini adalah kuadran kartesius. Gambar kuadran kartesius dapat dilihat pada gambar 1.

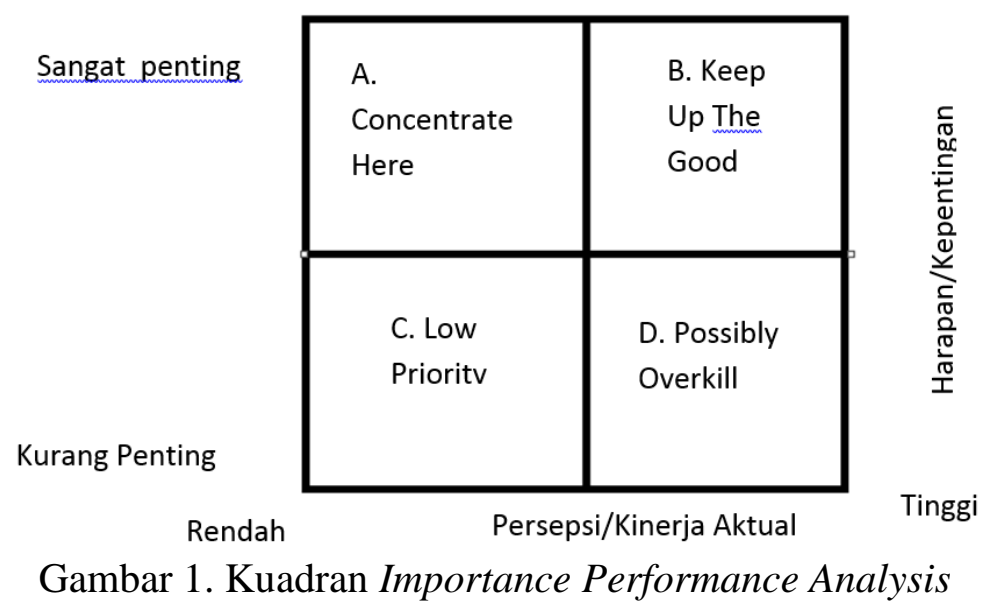

Sumber : Brandt, 2000 
Dalam menginterpretasi kuadran, keduanya merinci sebagai berikut:

A. Concentrate Here (konsentrasi di sini).

Faktor-faktor di dalam kuadran ini dianggap sebagai faktor yang Penting dan diharapkan oleh konsumen tetapi kondisi Persepsi dan Kinerja Aktual yang ada pada saat ini belum memuaskan sehingga pihak manajemen berkewajiban mengalokasikan sumber daya untuk meningkatkan.

B. Keep up with the good work (pertahankan prestasi).

Faktor-faktor yang terletak pada kuadran ini dianggap penting dan diharapkan sebagai faktor penunjang bagi kepuasan konsumen sehingga pihak manajemen berkewajiban dapat terus mempertahankan prestasi yang telah dicapai.

\section{Low Priority (prioritas rendah)}

Faktor-faktor yang terletak pada kuadran ini mempunyai tingkat Persepsi atau Kinerja aktual yang rendah sekaligus dianggap tidak terlalu Penting oleh konsumen sehingga manajemen tidak perlu terlalu memberikan perhatian.

D.Possibly Overkill (terlalu berlebih).

Faktor-faktor yang terletak pada kuadran ini dianggap Tidak Terlalu Penting dan tidak terlalu diharapkan sehingga pihak manajemen tidak perlu mengalokasikan sumber daya untuk faktorfaktor tersebut.

\section{ANALISIS DAN PEMBAHASAN}

\section{Hasil Perhitungan Aspek Transportasi Berdasarkan Suvei Lapangan}

a. Kapasitas Parkir

Setelah melakukan survei lapangan, didapat jumlah total stall/ slot parkir di tempat peristirahatan pada hari jumat adalah 270 slot dan minggu 321 slot. Jumlah parkir pada hari jumat 270 merupakan petak parkir yang pasti, namun terdapat 51 petak parkir yang fleksibel dalam arti bisa digunakan untuk parkir apabila kebutuhan parkir diperlukan. Seperti pada hari minggu dimana jam puncak terjadi.

\section{b. Data Keluar Masuk Kendaraan}

Data keluar masuk kendaraan yang di survei dengan mencatat waktu saat kendaraan masuk dan keluar pada hari jumat dan hari minggu. Waktu yang diperlukan untuk mensurvei adalah 4 jam karena dalam rentang waktu tersebut, jam puncak telah masuk didalamnya. Survei dilakukan 2 kali pada hari: jumat, 4 mei 2018 jam 17.00 - 21.00 dengan cuaca mendung dan minggu, 6 mei 2018 jam 13.00 - 17.00 dengan cuaca cerah.

\section{c. Durasi Parkir}

Data diperoleh dengan membandingkan waktu keluar dan masuk kendaraan ke tempat peristirahatan, maka akan di dapatkan durasi tiap kendaraan di tempat peristirahatan. Data durasi parkir pada hari jumat: $\overline{D P}=\Sigma \mathrm{DP} / \mathrm{n}=352: 12: 07 / 300$ kendaraan $=1$ jam 10 menit.

Data durasi parkir pada hari minggu: $\overline{D P}=\Sigma \mathrm{DP} / \mathrm{n}=1377: 01: 15 / 1443$ kendaraan $=57$ menit.

\section{d. Indeks Parkir}

Indeks parkir adalah perbandingan antara akumulasi parkir dengan kapasitas ruang parkir yang tersedia. Nilai indeks parkir ini dapat menunjukkan seberapa besar kapasitas parkir yang telah terisi. Indeks parkir dihitung setiap 1/2 jam sesuai dengan periode. 
1). Hari Jumat, Slot parkir $=270$ kendaraan

○ Jam $17.00-17.30$

Akumulasi $=227+72-80=219$ kendaraan

I $=\frac{219}{321}=0,6822<1$, kapasitas lebih besar dari kebutuhan parkir.

○ Jam $17.30-18.00$

Akumulasi $=218+59-76=201$ kendaraan

Ip $=\frac{201}{321}=0,6262<1$, kapasitas lebih besar dari kebutuhan parkir.

○ Jam $18.00-18.30$

Akumulasi $=218+66-83=201$ kendaraan

I $=\frac{201}{321}=0,6262<1$, kapasitas lebih besar dari kebutuhan parkir.

2) Hari Minggu, Slot parkir $=321$ kendaraan

○ Jam $15.30-16.00$

Akumulasi $=307+210-160=357$ kendaraan

I $=\frac{357}{321}=1,1122>1$, kebutuhan parkir lebih besar dari kapasitas.

○ Jam $16.00-16.30$

Akumulasi $=305+221-194=332$ kendaraan

Ip $=\frac{332}{321}=1,0343>1$, kebutuhan parkir lebih besar dari kapasitas.

○ Jam $16.30-17.00$

Akumulasi $=313+184-152=345$ kendaraan

Ip $=\frac{345}{321}=1,0748>1$, kebutuhan parkir lebih besar dari kapasitas.

\section{e. Denah Site Layout}

Site layout yang ada mencakup tata letak dan posisi bangunan, letak taman bermain, jumlah slot parkir kendaraan dan alur lalu lintas. Gambar ada 2 variasi yaitu hari jumat dan hari minggu, perbedaannya adalah jumlah slot parkir, dimana pada hari jum'at (weekday) jumlah slot parkir 270 dan pada hari minggu (weekend) jumlahnya 321 kendaraan. Site layout dapat dilihat pada gambar 2 dan gambar 3.

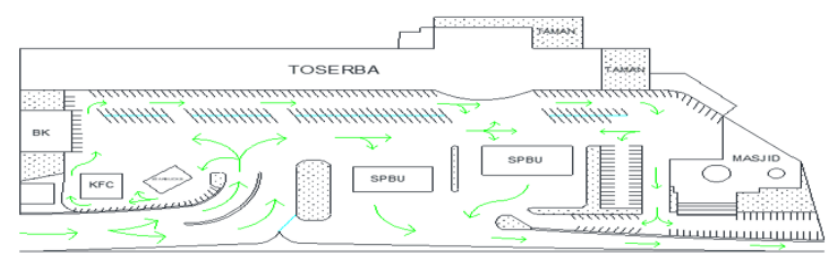

DENAH SITE LAYOUT REST AREA KM 97 TOL CIPULARANG
SKALA 1:100

Gambar 2. Denah Site Layout Hari Jumat

Sumber: Penulis, 2019

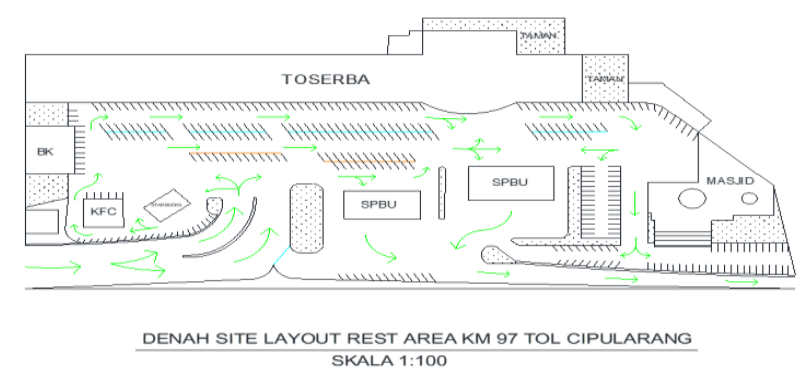

Gambar 3. Denah Site Layout Hari Minggu

Sumber: Penulis, 2019 
Hubungan antara kapasitas parkir dan akumulasi parkir dengan persepsi durasi memperoleh tempat parkir, persepsi memperoleh tempat parkir dan persepsi kapasitas tempat parkir

Data tingkat kepuasan penumpang dari kuisioner yang telah disebarkan di hitung dengan menggunakan metode IPA yaitu mempergunakan nilai mean persepsi dari setiap pertanyaan, Sedangkan untuk mean harapan yang dipergunakan 5, dengan asumsi harapan tertinggi 5. Pada aspek pelayanan transportasi dan aspek pelayanan umum diperoleh tingkat kesesuaian dan tingkat kesenjanga (gap) yang terdiri dari 8 pelayanan adalah sebagai berikut :

Tabel 3 Hasil Importance Performance Analysis

\begin{tabular}{|c|c|c|c|c|c|}
\hline Poin & Pelayanan Transportasi & $\begin{array}{c}\text { Mean } \\
\text { Persepsi }\end{array}$ & $\begin{array}{c}\text { Mean } \\
\text { Harapan }\end{array}$ & Gap & TKi\% \\
\hline 1 & $\begin{array}{l}\text { Akses dari jalan tol menuju ke tempat } \\
\text { peristirahatan. }\end{array}$ & 4.32 & 5 & 0.68 & 86.4 \\
\hline 2 & $\begin{array}{l}\text { Kondisi permukaan jalan di dalam area } \\
\text { tempat peristirahatan. }\end{array}$ & 4.07 & 5 & 0.93 & 81.4 \\
\hline 3 & $\begin{array}{l}\text { Kondisi permukaan jalan di jalur masuk } \\
\text { (ramp in) }\end{array}$ & 3.97 & 5 & 1.03 & 79.4 \\
\hline 4 & $\begin{array}{l}\text { Kondisi permukaan jalan di jalur keluar } \\
\text { (ramp out) }\end{array}$ & 3.93 & 5 & 1.07 & 78.6 \\
\hline 5 & $\begin{array}{l}\text { Kejelasan dan ketepatan petunjuk arah } \\
\text { dalam area tempat peristirahatan. }\end{array}$ & 3.71 & 5 & 1.29 & 74.2 \\
\hline 6 & Ketersediaan jumlah tempat parkir & 3.49 & 5 & 1.51 & 69.8 \\
\hline 7 & Luas satu petak tempat parkir kendaraan & 3.99 & 5 & 1.01 & 79.8 \\
\hline 8 & $\begin{array}{l}\text { Akses menuju ke stasiun pengisian bahan } \\
\text { bakar. }\end{array}$ & 4 & 5 & 1 & 80 \\
\hline 9. & Ketersediaan toilet umum & & & & \\
\hline 10 & Fungsi dan kebersihan toilet umum. & 3.89 & 5 & 1.11 & 77.8 \\
\hline 11 & $\begin{array}{l}\text { Fasilitas lampu penerangan di area } \\
\text { peristirahatan pada malam hari. }\end{array}$ & 3.91 & 5 & 1.09 & 78.2 \\
\hline 12 & $\begin{array}{l}\text { Ketersediaan fasilitas tempat makan dan } \\
\text { minum di tempat peristirahatan. }\end{array}$ & 4.25 & 5 & 0.75 & 85 \\
\hline 13 & $\begin{array}{l}\text { Fungsi dan kebersihan tempat makan dan } \\
\text { minum di tempat peristirahatan. }\end{array}$ & 4 & 5 & 1 & 80 \\
\hline 14 & $\begin{array}{l}\text { Ketersediaan tempat beribadah untuk } \\
\text { pengunjung. }\end{array}$ & 4.21 & 5 & 0.79 & 84.2 \\
\hline 15 & Fungsi dan kebersihan tempat beribadah. & 4.15 & 5 & 0.85 & 83 \\
\hline 16 & Jumlah stasiun pengisian bahan bakar. & 4 & 5 & 1 & 80 \\
\hline & Sum & 108.911 .875 & 135 & 260.881 & 2178 \\
\hline & Average & 9.075 .989 .583 & 11.25 & 217.401 & 182 \\
\hline
\end{tabular}

Penjelasan setiap poin faktor pelayanan adalah sebagai berikut:

Poin 1. Akses dari jalan tol menuju ke tempat peristirahatan sudah baik dengan nilai gap 0,68 dan tingkat kepuasan responden $86,4 \%$ (sangat baik).

Poin 2. Sirkulasi yang lancar tergantung pada kondisi perkerasan di dalam tempat peristirahatan. Persepsi responden sudah baik.

Poin 3. Kondisi permukaan yang terbilang cukup baik sehingga tidak menghambat sirkulasi lalu lintas untuk masuk ke dalam tempat peristirahatan. Perhatian pengelola terhadap poin 3 tetap di perlukan untuk mencapai harapan pengunjung karena nilai gap pada poin ini sebesar 1,03. 
Poin 4. Pengunjung merasa sudah cukup puas terhadap kondisi perkerasan di ramp out.

Poin 5. Sudah terdapat petunjuk arah tetapi belum cukup, responden menyatakan bahwa petunjuk arah membingungkan untuk pengunjung yang baru pertama kali.

Poin 6. Ketersediaan jumlah tempat parkir untuk kendaraan terbilang kurang di saat jam puncak. Terbukti dari gap responden sebesar 1,51 dan tingkat kepuasan hanya sebesar 69,8\% (baik).

Poin 7. Luas satu slot tempat parkir sudah baik dengan nilai gap hanya sebesar 1,01. Namun dibeberapa titik terdapat slot parkir yang terlalu sempit.

Poin 8. Akses menuju SPBU sudah baik. Tingkat kepuasan sebesar $80 \%$ (sangat baik).

Poin 9. Ketersediaan toilet umum di tempat peristirahatan sudah mencukupi dengan nilai gap hanya sebesar 0,86 .

Poin 10. Fungsi dan kebersihan toilet umum sudah cukup baik, dengan alat pelayanan yang masih berfungsi dengan baik namun kebersihan perlu di jaga karena banyaknya jumlah pengunjung.

Poin 11. Fasilitas lampu penerangan di area peristirahatan pada malam hari sudah cukup baik. Tingat kepuasan responden sebesar 78,2\% (baik).

Poin 12. Ketersediaan fasilitas tempat makan dan minum sudah baik. Terbukti dari kepuasan responden sebesar $85 \%$ (sangat baik).

Poin 13. Fungsi dan kebersihan tempat makan dan minum yang terbilang cukup baik dengan nilai persepsi responden sebesar 4 dari nilai tertinggi yaitu 5 .

Poin 14. Ketersediaan tempat beribadah sudah sangat baik dibanding dengan pelayananyang lain. Terbukti dari tingkat kepuasan pengunjung yang besar yaitu $84,2 \%$ (sangat baik). Tempat ibadah di tempat peristirahatan 97 merupakan yang terbesar

Poin 15. Fungsi dan kebersihan tempat beribadah juga terbilang baik dengan nilai persepsi sebesar 4,15 dari nilai tertinggi yaitu 5 .

Poin 16. Jumlah stasiun pengisian bahan bakar yang baik dengan nilai kepuasan sebesar $80 \%$ (sangat baik).

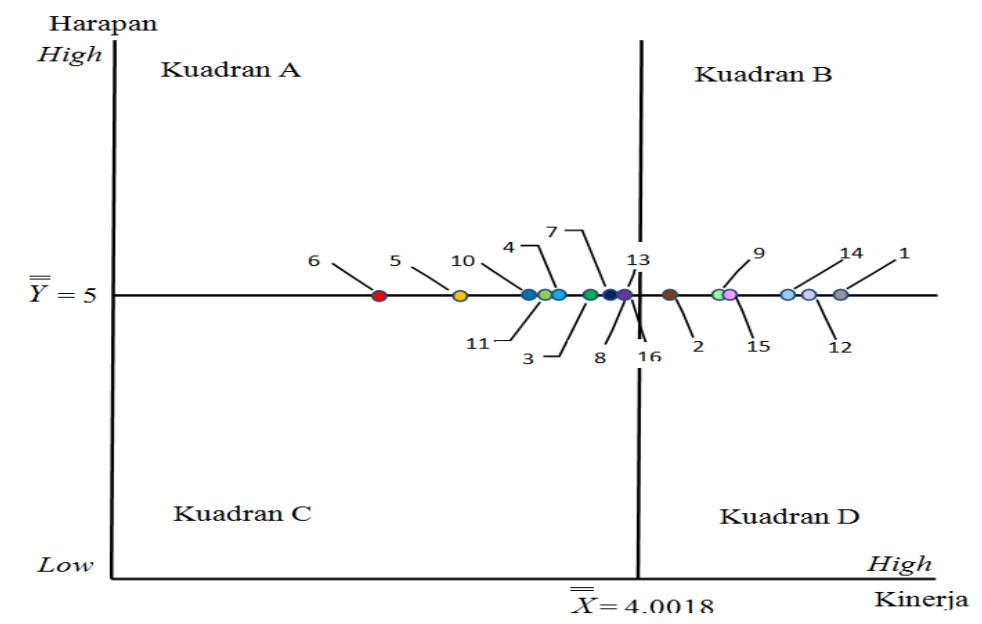

Gambar 4. Diagram Kartesius Importance Performance Analysis Sumber: Penulis, 2019

\section{Hubungan Hasil Survei Observasi Aspek Transportasi Dengan Hasil Survei Kuisioner}

Data survei lapangan berhubungan langsung dengan denah site layout dan denah parkir. Bentuk korelasi ini menghasilkan hubungan persepsi responden terhadap fasilitas dan kenyataan langsung dari survei lapangan. Data yang diperoleh dari hasil survei di lapangan adalah data kepuasan pengujung dan data survei aspek transportasi dimana kedua data tersebut saling 
berpengaruh satu sama lain. Pengaruh tersebut tidak dapat di analisa apabila data yang diperoleh hanya salah satu dari data diatas. Hasil analisa terbagi menjadi dua yaitu hubungan antara aspek transportasi dengan persepsi dan hubungan pelayanan umum dengan SPM. Berikut adalah hubungan antara aspek transportasi dengan persepsi.

a. Akumulasi parkir kendaraan pada: hari jumat jam 17.00 - 17.30 adalah sebanyak 219 kendaraan < kapasitas parkir 270 kendaraan dan pada hari minggu jam 15.30 - 16.00 sebesar 357 kendaraan > kapasitas parkir tersedia yaitu 321 kendaraan.

Meskipun pada persepsi memperoleh tempat parkir menjawab pernah tidak memperoleh tempat parkir, persepsi durasi memperoleh tempat parkir rata-rata selama 2-5 menit dan kapasitas tempat parkir rata-rata menjawab baik, tetapi data perbandingan antara akumulasi parkir dan kapasitas parkir pada hari minggu kebutuhan > kapasitas.

b. Hubungan antara durasi dengan persepsi durasi parkir, durasi parkir rata-rata hasil observasi hari jumat adalah 1 jam 10 menit dan hari minggu 57 menit. Persepsi durasi parkir sebagian besar menjawab 30-60 menit menunjukan bahwa hasil dari persepsi mendekati hasil yang diperoleh pada survei lapangan.

c. Hubungan antara indeks parkir dengan persepsi hambatan pada sirkulasi di dalam rest area dan akses menuju SPBU. Meskipun persepsi sirkulasi rata-rata menjawab jarang terjadi hambatan dan persepsi akses menuju SPBU sebagian besar menjawab baik. Sedangkan menurut observasi indeks parkir pada: hari jumat 0,62 - 0,69 dan minggu berkisar 1,03 $1,12>1$ yang mengindikasikan bahwa kapasitas lebih kecil dari kebutuhan.

d. Hubungan antara ketepatan rambu penunjuk arah dengan persepsi petunjuk arah mencari tempat parkir. Persepsi petunjuk arah mencari tempat parkir hanya beberapa responden yang menjawab pernah membingungkan dan persepsi ketepatan petunjuk arah rata-rata menjawab baik. Hasil dari survei lapangan menunjukan petunjuk arah sudah cukup jelas. Namun karena kondisi tempat parkir yang sifatnya fleksibel, maka ada titik (posisi tertentu) yang tidak dilengkapi dengan petunjuk arah, sehingga akan membingungkan pengemudi yang jarang.

e. Hubungan antara kondisi perkerasan dengan persepsi kondisi perkerasan pada jalan masuk, keluar dan di dalam rest area. Dari data persepsi, rata-rata responden menjawab baik dan dari hasil survei lapangan menunjukan bahwa lubang terdapat di beberapa titik seperti pada jalur masuk, keluar dan di dalam rest area. Dari persepsi dan survei kondisi di lapangan dapat disimpulkan bahwa kedua data tersebut sesuai.

\section{Hubungan antara data persepsi dengan SPM Fasilitas Pelayanan}

a. Hubungan antara persepsi jumlah SPBU dengan SPM, dari persepsi jumlah stasiun SPBU rata-rata menjawab baik dan hasil survei lapangan diperoleh jumlah stasiun pengisian sebanyak 10 buah sedangkan menurut SPM adalah 4 buah.

b. Hubungan antara persepsi jumlah toilet dengan SPM, dari persepsi jumlah toilet sebagian besar menjawab sangat baik, dari hasil survei lapangan didapat jumlah toilet sebanyak 3 buah, urinal toilet pria 28 buah $>20$ buah, WC toilet pria $39>7$ buah dan WC toilet wanita sebanyak $47>20$ buah. hasil survei lapangan didapat jumlah toilet telah melebihi SPM.

c. Hubungan antara persepsi fungsi dan kebersihan fasilitas pelayanan dengan SPM.dari persepsi fungsi dan kebersihan fasilitas pelayanan sebagian besar menjawab baik. SPM memiliki tolak ukur toilet yang berfungsi $100 \%$ dan bersih. Dari hasil observasi di dapat fungsi dan kebersihan fasilitas pelayanan memenuhi SPM dan persepsi responden. 


\section{KESIMPULAN DAN SARAN}

\section{Kesimpulan}

Adapun kesimpulan dari hasil analisis dalam penelitian ini yaitu:

a. Kebutuhan parkir pada hari minggu 357 kendaraan > dari pada kapasitas parkir kendaraan yang tersedia 321. Sedangkan pada saat week day, kapasitas parkir masih dapat memenuhi dimana kebutuhan 219 kendaraan $<$ kapasitas parkir $=270$ kendaraan.

b. Luas lahan Tempat Peristirahatan KM 97 Tol Cipularang<dari kebutuhannya yang berdampak pada: luas tempat parkir, sehingga memperlambat arus lalu lintas di dalam rest area yang menghambat sirkulasi lalu lintas, sehingga akses dari 1 lokasi ke yang lain terhambat.

- Kebutuhan parkir yang > kapasitasnya membuat pengelola merekayasa dengan lokasi parkir fleksibel, menggunakan cone dan tali untuk membuat slot parkir baru, namun dampaknya adalah: Luas jalan di area parkir menjadi lebih sempit, secara tidak langsung menciptakan lajur lalu lintas yang baru di antara lokasi parkiran, sehingga semakin banyak lajur lalu lintas diantara slot parkir akan memperlambat.

- Dengan adanya lahan parkiran yang fleksibel ini maka pengelola tidak dapat menyediakan petunjuk arah (rambu dan marka) yang permanen sehingga pada beberapa titik tidak terdapat petunjuk arah.

- Kurangnya petunjuk arah mengakibatkan pengunjung yang jarang datang menjadi bingung meskipun terdapat petugas yang membantu melayani untuk menunjukan arah.

c. Fasilitas pelayanan di tempat peristirahatan dinilai sudah cukup baik. Meskipun begitu, hasil dari pengelompokan data menggunakan metode IPA menyatakan bahwa poin-poin tersebut sebagian masih berada di kuadran concentrate here. Hal tersebut menunjukkan perlu perhatian lebih dari pihak pengelola agar dapat mencapai harapan yang diinginkan.

d. Tingkat kepuasan responden terhadap seluruh poin mengenai keandalan dari infrastruktur tempat peristirahatan baik dari segi aspek transportasi maupun fasilitas pelayanan mendapatkan nilai sebesar $80,32 \%$ yang berarti sangat baik.

e. Perkerasan pada jalur keluar - masuk dan di dalam rest area sudah cukup baik dengan nilai kepuasan sebesar 78,6 - 81,4\% yang berarti sudah baik meskipun masih perlu perawatan pada jalan yang berlubang.

\section{Saran}

Mengadakan perluasan tempat peristirahatan sehingga dapat memperluas kebutuhan tempat parkir.

\section{REFERENSI}

Agustinah, U. et al. (2015).” Perencanaan dan Perancangan Rest area Wilayah Suramadu Di Kabupaten Bangkalan Madura". Prosiding Seminar Nasional Sains dan Teknologi Terapan III, 617-626.

Atmi, F. W.et al. (2014),” Rest area Jalan Raya Sragen-Ngawi KM.14 Sragen”. IMAJI, 3, 181188.

Abubakar, I. (2011), Parkir: Pengantar Perencanaan dan Penyelenggaraan Fasilitas Parkir. Transindo Gastama Media, Jakarta.

Chandra, PA. (2012). "Rest area Di Mantingan Kabupaten Ngawi".

Departemen Perhubungan Direktur Jenderal Perhubungan Darat. (1996). Pedoman Teknis Penyelenggaraan Fasilitas Parkir. Departemen Perhubungan, Jakarta.

Munawar, A. (2004). Manajemen Lalulintas Perkotaan. Beta Offset, Yogyakarta. 
Murwono, J. (1996). "Pengantar Teknik dan Perencanaan Transportasi". UGM Yogyakarta.

Peraturan Pemerintah Republik Indonesia Nomor 2 Tahun 2018. "Standar Pelayanan Minimal,".

Peraturan Pemerintah Republik Indonesia Nomor 15 Tahun 2015. "Tentang Jalan Tol”.

Putranto, Leksmono. (2013). Rekayasa Lalu-Lintas. Edisi 2. PT Indeks, Jakarta.

Setyo, A.Y. (2010). Rest area Sebagai Fasilitas Transit Bagi Pengguna Jalan Raya Saradan Kawasan Hutan Jati Sektor II Madiun. Surakarta.

Wikrama Jaya. (2014). "Analisa Aspek Transportasi". 
